\title{
Selecting Postharvest Technology Method for Citrus Fruit using Analytic Hierarchy Process (AHP)
}

\author{
Andi Dirpan ${ }^{*}$ and Alim Setiawan Slamet ${ }^{2,3}$ \\ ${ }^{1}$ Department of Agricultural Technology, Faculty of Agricultural \\ Hasanuddin University, Jl. Perintis Kemerdekaan, Makassar, Indonesia. \\ ${ }^{2}$ The United Graduate School of Agricultural Science, Ehime University, Japan \\ ${ }^{3}$ Department of Management, Faculty of Economic and Management \\ Bogor Agricultural University, Bogor, Indonesia \\ Email: dirpan@unhas.ac.id*
}

\begin{abstract}
Ehime Prefecture is one of the main citrus fruit producing regions in Japan. As many as 20 major citrus varieties are cultivated in Ehime annually. The harvest of citrus fruit in a large scale has brought the consequences in the postharvest deterioration. It could be caused by many factors, including metabolic changes, (biochemical changes associated with respiratory metabolism, ethylene biosynthesis and action, and compositional changes), growth and development (anatomical and morphological changes), physical injuries, water loss, physiological disorders, and pathological To reduce these losses, it is suggested to apply proper handling methods or postharvest technologies that delay senescence and maintain the best possible quality. There are some handling methods or postharvest technologies that can be used to maintain the quality of citrus fruit, such as: modified atmosphere packaging (MAP), controlled atmosphere storage (CAS), coatings, hot water treatment, and etc. In this paper, analytic hierarchy process (AHP) is used to select the best postharvest method for preserving citrus fruit in Ehime. The ability of the AHP to provide selection of the postharvest technology with process flexibility like criteria selection, technology selection and criteria weightages allows its use by students, researchers, entrepreneurs, technology facilitators, policy makers, etc.
\end{abstract}

Keywords: Analytic hierarchy process, postharvest, citrus.

\section{INTRODUCTION}

Postharvest deterioration of citrus fruit could be caused by many factors, including metabolic changes, (biochemical changes associated with respiratory metabolism, ethylene biosynthesis and action, and compositional changes), growth and development (anatomical and morphological changes), physical injuries, water loss, physiological disorders, and pathological breakdown. On the other hand, citrus postharvest quality and shelf life are becoming increasingly aspects, as consumers expect the quality fruit to be available throughout the year (Ladaniya 2008). Therefore, harvesting and handling hold the key to getting desired results from postharvest treatments.

There are some handling methods or postharvest technologies can be used to maintain the quality of citrus fruit, such as: modified atmosphere packaging (MAP)(Kader and Zagory 1989; Porat et al. 2004; Techavises and Hikida 2008; Zagory and Kader 1988) and controlled atmosphere storage (CAS) (Dirpan and Hikida 2015), coating or waxing(BenYehoshua, Burg, and Young 1985; Chien, Sheu, and Lin 2007; Hagenmaier and Baker 1993; Park 1999), hot water treatment(Hong, Lee, and Kim 2007; Porat et al. 2000) and hot calcium dip (Nutakorn, Yoshio, and Toshio 2011). However, every method has drawbacks and advantages in preserving citrus fruit. Therefore, the first objective of this research is to select the best postharvest technology using analytic hierarchy process (AHP).

Analytic hierarchy process (AHP) has been applied to a variety of agriculture (Alphonce 1997; Chavez, Berentsen, and Oude Lansink 2012; Xu, Da, and Chen 2003). However, little attention has been given so far to the application of the AHP to the postharvest technology, although the AHP 
seems to be suitable also to sector of postharvest technology (Vera-Montenegro, Baviera-Puig, and García-Álvarez-Coque 2014). The other main reason of this study is to contribute to the solution of the postharvest problem. The first step begins by defining the final objective of the problem, its inherent factors (criteria, sub criteria and so on) and the options that enable the objective in question to be achieved. The next step consists in arranging the various elements into a hierarchy and estimating them, attributing to each element a numerical judgment corresponding to a qualitative assessment. Using the AHP, said data are subsequently processed to arrive at an evaluation of the order of importance of the various options in terms of the final objective.

\section{DATA AND METHOD}

\subsection{Study area}

Ehime Prefecture is located on the island of Shikoku, which is best known as a citrus kingdom in Japan. Absolute Location is $132^{\circ} 76^{\prime}$ East Longitude $33^{\circ} 83^{\prime}$ North Latitude.

\subsection{The analytic hierarchy process}

This study was quantitative research which employed the application of AHP for selecting postharvest technology method for citrus fruit in Ehime prefecture, Japan. The AHP method is one of the multi-criteria decision analyses, and is applicable to solving problems containing more than one decision criterion. This method is a mathematically based, was introduced by Saaty (1990). It uses the pairwise comparison method to rank order alternatives of a problem that are formulated and solved in a hierarchical structure. Briefly, the step-by-step procedure in using AHP is the following (Bevilacqua and Braglia 2000):

1. Define decision criteria in the form of a hierarchy of objectives. The hierarchy is structured in different levels: from the top (i.e. the goal) through intermediate levels (criteria and sub-criteria on which subsequent levels depend) to the lowest level (i.e. the alternatives). In this study, we are dealing with a multiple decision problem, the aim of which is to select postharvest technology for fruit citrus. The hierarchical model of this problem is presented in Fig. 1. The highest level of the hierarchy is the goal of the problem, the second level is the criteria as applied to the ranking of postharvest technology (improving quality, increasing shelf life, reducing cost and applicability), while the third one is the decision variants, i.e. modified atmosphere packaging (MAP), controlled atmosphere storage (CAS), coatings, hot water treatment (HWT), and hot calcium dip (HCD).

2. Weight the criteria, sub-criteria and alternatives as a function of their importance for the corresponding element of the higher level. For this purpose, AHP uses simple pairwise comparisons to determine weights and ratings so that the analyst can concentrate on just two factors at one time. One of the questions which could be asked in using a pairwise comparison is: how important is the "improving quality" factor with respect to the "increasing shelf life", in terms of the goal for "selecting postharvest technology method for Citrus fruit?" The answer may be "equally important", "moderately more important", etc. The verbal responses are then quantified and translated into a score via the use of discrete 9-point scales that we can see in Table 1 . In principle, the evaluators are expected to express their ratings in odd numbers $(1,3,5,7$ and 9$)$, while even numbers (2, 4, 6 and 8 ) are used where there is no consensus in the group of evaluators.

Table 1. Judgement scores in AHP.

\begin{tabular}{|l|l|c|}
\hline Judgement & \multicolumn{1}{|c|}{ Explanation } & Score \\
\hline \hline Equally & $\begin{array}{l}\text { Two attribute contribute } \\
\text { equally to the upper-level } \\
\text { criteria }\end{array}$ & 1 \\
\hline Between equally and moderately & 2 \\
\hline Moderately & $\begin{array}{l}\text { Experience and judgement } \\
\text { slightly favour one attribute } \\
\text { over another }\end{array}$ & 3 \\
\hline Between moderately and strongly & 4 \\
\hline Strongly & $\begin{array}{l}\text { Experience and judgement } \\
\text { strongly favour one attribute } \\
\text { over another }\end{array}$ & 5 \\
\hline Between strongly and very strongly & 6 \\
\hline $\begin{array}{l}\text { Very } \\
\text { strongly }\end{array}$ & $\begin{array}{l}\text { An attribute is strongly } \\
\text { favoured and its dominance } \\
\text { demonstrated in practice }\end{array}$ & 7 \\
\hline Between very strongly and extremely & 8 \\
\hline Extremely & $\begin{array}{l}\text { The evidence favouring one } \\
\text { attribute over another is of the } \\
\text { highest possible order of } \\
\text { affirmation }\end{array}$ & 9 \\
\hline
\end{tabular}




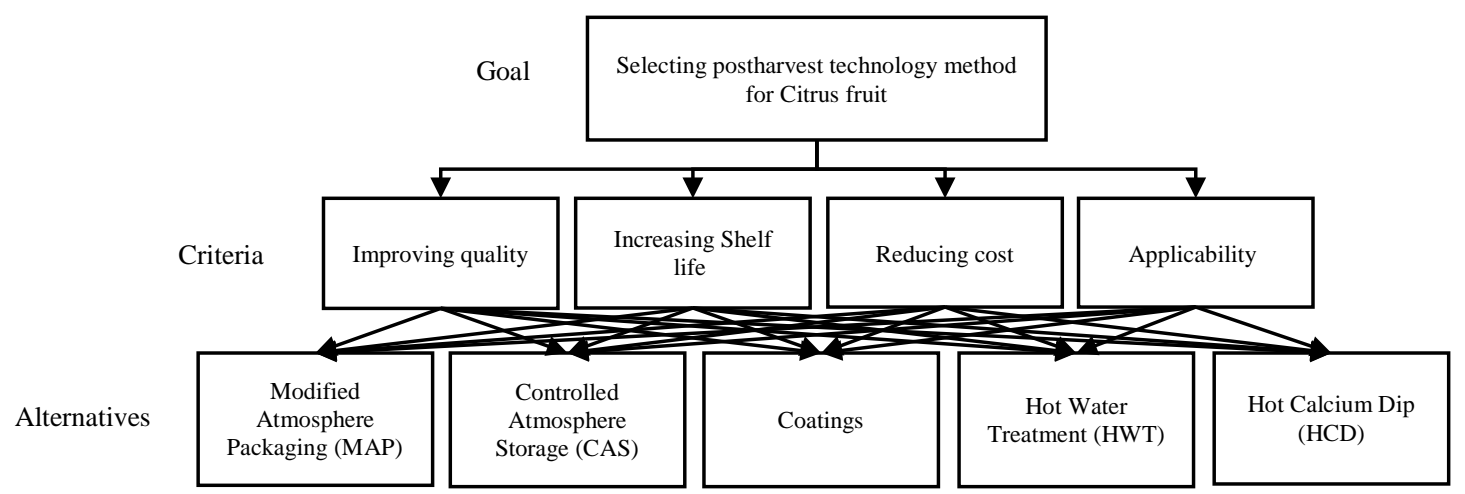

Figure 1. A hierarchical model of decision making problem concerning selecting postharvest method for Citrus fruit in Ehime

3. After a judgment matrix has been developed, a priority vector to weight the elements of the matrix is calculated. Priority vectors $(\mathrm{w})$ are obtained from the pairwise comparison matrix (A) by solving an eigenvalue problem in the following relation (Eq. 1):

$$
A w=\lambda_{\max } w
$$

where $\lambda_{\max }$ is the highest matrix eigenvalue.

4. Evaluate the soundness of the judgements with the inconsistency ratio $I_{R}$. This is a peculiarity of the AHP technique. Before determining an inconsistency measurement, it is necessary to introduce the consistency index (CI) of an $n \times n$ matrix (of judgements) defined by the ratio (Eq. 2):

$$
C I=\frac{\lambda_{\max }-n}{n-1}
$$

Then, $I_{R}$ is defined as the ratio (Eq. 3):

$$
I_{R}=\frac{C I}{R I}
$$

where RI is the corresponding average random value of CI for an $n \times n$ matrix. Judgements can be considered acceptable if $I_{R} \leqslant 0.1$. In cases of inconsistency, the assessment process is immediately repeated for the inconsistent matrix. An inconsistency ratio of 0.1 or more may warrant further investigation. Analyses using the AHP method can be performed easily and quickly with the support of numerous available IT tools. In this study, all AHP analyses were performed using the Super decisions tool.

\section{RESULTS AND DISCUSSION}

Based on the hierarchical model (Fig. 1), there are two types of pairwise comparisons in this study. The first type describes pairwise comparisons of elements of the criteria with respect to the goal as shown in Table 2. One of the question being asked is this: "Comparing improving quality and increasing shelf life, which one more dominates for the selecting postharvest technology method for Citrus fruit and by how much important?” The resulting priority vector, the maximum eigenvalue $\left(\lambda_{\max }\right)$ and the inconsistency ratio $\left(\mathrm{I}_{\mathrm{R}}\right)$ are shown in Table 2.

The second type describes pairwise comparisons of the elements of postharvest technology alternatives with respect to their parent criteria element as shown in Table 3, 4, 5 and 6 . For the example, the question being asked in Table 3 is this: "Comparing modified atmosphere packaging and controlled atmosphere storage, which one more dominates the improving quality criteria, and by how much important?" The tables present the local priority vectors of each pairwise comparisons matrix with their corresponding maximum eigenvalues and inconsistency ratio $\left(I_{R}\right) . \quad I_{R}$ values range from 0.049 to 0.094 which satisfy the 0.10 threshold. By multiplying local priority vector criteria from Tables 2 and local priority vector alternatives from Table 3, 4, 5, and 6 in matrix form, the product is the global priority vector or final weights of the postharvest technology alternatives, which reflected in Table 7 . From Table 7, we can conclude that by using AHP, the best postharvest technology for preserving citrus fruit is MAP followed by CAS, coatings, HCD and HWT respectively. 
Table 2. Pairwise comparisons of elements of the criteria with respect to the goal.

\begin{tabular}{|l|c|c|c|c|c|}
\hline \multicolumn{1}{|c|}{ Goal } & $\begin{array}{c}\text { Improving } \\
\text { quality }\end{array}$ & $\begin{array}{c}\text { Increasing } \\
\text { shelf life }\end{array}$ & $\begin{array}{c}\text { Reducing } \\
\text { cost }\end{array}$ & Applicability & $\begin{array}{c}\text { Local priority } \\
\text { vector }\end{array}$ \\
\hline \hline Improving quality & 1 & 6 & 6 & 4 & 0.636 \\
\hline Increasing shelf life & $1 / 6$ & 1 & 1 & 1 & 0.117 \\
\hline Reducing cost & $1 / 6$ & 1 & 1 & 1 & 0.117 \\
\hline Applicability & $1 / 4$ & 1 & 1 & 1 & 0.130 \\
\hline
\end{tabular}

$\lambda_{\max }=4.021, \mathrm{I}_{\mathrm{R}}=0.007$

Table 3. Pairwise comparisons of elements of the alternatives with respect to the improving quality criteria.

\begin{tabular}{|l|c|c|c|c|c|c|}
\hline $\begin{array}{c}\text { Improving } \\
\text { quality }\end{array}$ & MAP & CAS & Coatings & HWT & HCD & $\begin{array}{c}\text { Local priority } \\
\text { vector }\end{array}$ \\
\hline \hline MAP & 1 & 1 & 6 & 6 & 6 & 0.386 \\
\hline CAS & $1 / 3$ & 1 & 6 & 6 & 7 & 0.401 \\
\hline Coatings & $1 / 6$ & $1 / 6$ & 1 & 3 & 2 & 0.094 \\
\hline HWT & $1 / 6$ & $1 / 6$ & $1 / 3$ & 1 & $1 / 4$ & 0.042 \\
\hline HCD & $1 / 6$ & $1 / 7$ & $1 / 2$ & 4 & 1 & 0.077 \\
\hline
\end{tabular}

$\lambda_{\max }=5.349, \mathrm{I}_{\mathrm{R}}=0.078$

Table 4. Pairwise comparisons of elements of the alternatives with respect to the increasing shelf life criteria.

\begin{tabular}{|l|c|c|c|c|c|c|}
\hline $\begin{array}{c}\text { Increasing } \\
\text { shelf life }\end{array}$ & MAP & CAS & Coatings & HWT & HCD & $\begin{array}{c}\text { Local priority } \\
\text { vector }\end{array}$ \\
\hline \hline MAP & 1 & $1 / 2$ & 6 & 7 & 6 & 0.346 \\
\hline CAS & 2 & 1 & 6 & 6 & 6 & 0.443 \\
\hline Coatings & $1 / 6$ & $1 / 6$ & 1 & 4 & 3 & 0.108 \\
\hline HWT & $1 / 7$ & $1 / 6$ & $1 / 4$ & 1 & $1 / 3$ & 0.039 \\
\hline HCD & $1 / 6$ & $1 / 6$ & $1 / 3$ & 3 & 1 & 0.064 \\
\hline
\end{tabular}

Table 5. Pairwise comparisons of elements of the alternatives with respect to the reducing cost criteria.

\begin{tabular}{|l|c|c|c|c|c|c|}
\hline Reducing cost & MAP & CAS & Coatings & HWT & HCD & $\begin{array}{c}\text { Local priority } \\
\text { vector }\end{array}$ \\
\hline MAP & 1 & 7 & 5 & $1 / 2$ & 1 & 0.291 \\
\hline CAS & $1 / 7$ & 1 & $1 / 6$ & $1 / 5$ & $1 / 3$ & 0.044 \\
\hline Coatings & $1 / 5$ & 6 & 1 & 3 & 2 & 0.122 \\
\hline HWT & 2 & 5 & $1 / 3$ & 1 & 2 & 0.351 \\
\hline HCD & 1 & 3 & $1 / 2$ & $1 / 2$ & 1 & 0.191 \\
\hline
\end{tabular}

$\lambda_{\max }=5.416, \mathrm{I}_{\mathrm{R}}=0.093$

Table 6. Pairwise comparisons of elements of the alternatives with respect to the applicability criteria.

\begin{tabular}{|l|c|c|c|c|c|c|}
\hline Applicability & MAP & CAS & Coatings & HWT & HCD & $\begin{array}{c}\text { Local priority } \\
\text { vector }\end{array}$ \\
\hline \hline MAP & 1 & 1 & 4 & 3 & 3 & 0.334 \\
\hline CAS & 1 & 1 & 7 & 2 & 2 & 0.339 \\
\hline Coatings & $1 / 4$ & $1 / 7$ & 1 & 1 & 1 & 0.088 \\
\hline HWT & $1 / 3$ & $1 / 2$ & 1 & 1 & 1 & 0.136 \\
\hline
\end{tabular}




\begin{tabular}{|l|c|c|c|c|c|c|}
\hline $\mathrm{HCD}$ & $1 / 3$ & $1 / 2$ & 1 & 1 & 1 & 0.103 \\
\hline$\lambda_{\max }=5.219, \mathrm{I}_{\mathrm{R}}=0.049$ &
\end{tabular}

Table 7. Ranking of postharvest technology.

\begin{tabular}{|l|c|}
\hline \multicolumn{1}{|c|}{ Alternatives } & $\begin{array}{c}\text { Global priority } \\
\text { vector }\end{array}$ \\
\hline \hline $\begin{array}{l}\text { Modified Atmosphere } \\
\text { Packaging }\end{array}$ & 0.364 \\
\hline $\begin{array}{l}\text { Controlled Atmosphere } \\
\text { Storage }\end{array}$ & 0.356 \\
\hline Coatings & 0.098 \\
\hline Hot Calcium Dip & 0.092 \\
\hline Hot Water Treatment & 0.090 \\
\hline
\end{tabular}

\section{CONCLUSIONS}

The choice of postharvest technology method is considered by criteria such as improving quality, reducing cost, increasing shelf life and applicability. Moreover, one method may have drawbacks and advantages related to those criteria. In this work, our aim was to select the appropriate postharvest technology for of citrus fruit using AHP.

The finding indicated that the most important criteria for selecting postharvest technology is improving quality followed by applicability, increasing shelf life and reducing cost. Furthermore, the postharvest technology that had the highest importance is modified atmosphere packaging (MAP), controlled atmosphere storage (CAS), coatings, hot calcium dip (HCD) and hot water treatment (HWT).

\section{ACKNOWLEDGEMENT}

The author thank to the Directorate General of High Education (DGHE) of INDONESIA and Hasanuddin University for providing scholarship.

\section{REFERENCES}

Alphonce, Christian B. 1997. "Application of the Analytic Hierarchy Process in Agriculture in Developing Countries." Agricultural Systems 53(1): 97-112.

Ben-Yehoshua, S, S P Burg, and R Young. 1985. "Resistance of Citrus Fruit to Mass Transport of Water Vapor and Other Gases.” Plant physiology 79(6): 1048-53.

Bevilacqua, M, and M Braglia. 2000. "The Analytic Hierarchy Process Applied to
Maintenance Strategy Selection.” Reliability Engineering \& System Safety 70(1): 71-83.

Chavez, M. D., P. B M Berentsen, and a. G J M Oude Lansink. 2012. "Assessment of Criteria and Farming Activities for Tobacco Diversification Using the Analytical Hierarchical Process (AHP) Technique.” Agricultural Systems 111: 53-62.

Chien, Po Jung, Fuu Sheu, and Hung Ren Lin. 2007. "Coating Citrus (Murcott Tangor) Fruit with Low Molecular Weight Chitosan Increases Postharvest Quality and Shelf Life." Food Chemistry 100(3): 1160-64.

Dirpan, Andi, and Yoshio Hikida. 2015. "Effect of Various Citrus Sizes on the Resistance to Gas Diffusion." Procedia of Environmental Science - Elsevier 28: 391-98.

Hagenmaier, Robert D, and Robert A Baker. 1993. "Reduction in Gas Axchange of Citrus Fruit by Wax Coatings.” J. Agric. Food Chem 41: 283-87.

Hong, Seok I., Hyun H. Lee, and Dongman Kim. 2007. "Effects of Hot Water Treatment on the Storage Stability of Satsuma Mandarin as a Postharvest Decay Control." Postharvest Biology and Technology 43(2): 271-79.

Kader, A.A., and D Zagory. 1989. "Modified Atmosphere Packaging of Fruits and Vegetables." Critical Reviews in Food Science and Nutrition 28: 1-30.

Ladaniya, Milind. 2008. Citrus Fruit (BIOLOGY, TECHNOLOGY, AND EVALUATION. First Edit. ed. Milind S. Ladaniya. San Diego, USA: Elsevier.

Nutakorn, Techavises, Hikida Yoshio, and Kawano Toshio. 2011. “A Comparative Study of the Effects of Postharvest Treatments on Occurrence of Kohansho and Quality of 'Kiyomi' Tangor.” Food Preservation Science 37(4): 167-72.

Park, Hyun Jin. 1999. "Development of Advanced Edible Coatings for Fruits." Trends in Food Science and Technology 10(8): 254-60.

Porat, Ron, Avinoam Daus, Batia Weiss, Lea 
Cohen, Elazar Fallik, and Samir Droby. 2000. "Reduction of Postharvest Decay in Organic Citrus Fruit by a Short Hot Water Brushing Treatment.” Postharvest Biology and Technology 18(2): 151-57.

Porat, Ron, Batia Weiss, Lea Cohen, Avinoam Daus, and Nehemia Aharoni. 2004. "Reduction of Postharvest Rind Disorders in Citrus Fruit by Modified Atmosphere Packaging." Postharvest Biology and Technology 33(1): 35-43.

Techavises, Nutakorn, and Yoshio Hikida. 2008. "Development of a Mathematical Model for Simulating Gas and Water Vapor Exchanges in Modified Atmosphere Packaging with Macroscopic Perforations.” Journal of Food Engineering 85(1): 94-104.

Vera-Montenegro, Lenin, Amparo BavieraPuig, and José María García-ÁlvarezCoque. 2014. "Multi-Criteria Methodology: AHP and Fuzzy Logic in the Selection of Post-Harvest Technology for Smallholder Cocoa Production." International Food and Agribusiness Management Review 17(2): 107-24.

Xu, Shiying, Li Da, and Xiufang Chen. 2003. "Determining Optimum Edible ÿlms for Kiwifruits Using an Analytical Hierarchy Process.” Computers \& Operations Research 30(6): 877-86.

Zagory, D, and AA Kader. 1988. "Modified Atmosphere Packaging of Fresh Produce.” Food technology. 